\title{
O CAPITAL SIMBÓLICO DE MEDELLÍN E AS INTERVENÇÕES URBANAS NAS FAVELAS CARIOCAS
}

\author{
THE SYMBOLIC CAPITAL OF MEDELLIN AND URBAN INTERVENTIONS IN THE FAVELAS \\ OF RIO
}

\author{
Any Brito Leal Ivo ${ }^{1}$ \\ Pasqualino Magnavita ${ }^{2}$
}

\section{Resumo}

O texto busca refletir sobre algumas intervenções e projetos visitados em Medellin, apresentados mundialmente como ícones de um novo tempo. Essas intervenções tornam-se referenciais dos projetos de transformação do urbano e avançam como ações constituintes de uma dinâmica de cidade inserida em uma política de segurança mundialmente divulgada e reconhecida como exemplar. Esse texto busca não apenas a descrição e análise desses projetos, mas também objetiva estabelecer nexos às recentes intervenções do Estado brasileiro nas favelas do Rio de Janeiro, como partes de uma ação de segurança pública baseada na repressão/pacificação territorial - que sob diversos aspectos, especialmente os mais estruturais, se relacionam com Medellín.

Palavras-chave: Urbanismo, Violência, Medellin, Pacificação, Rio de Janeiro.

\section{Abstract}

This paper aims to reflect on some interventions and projects visited in Medellin, presented worldwide as icons of a new time. These interventions become benchmarks of urban transformation projects and advance as a constituent stock of a city dynamically inserted into a security policy globally publicized and recognized as exemplary. This text searches not only the description and analysis of these projects, but also aims to establish links to the recent intervention by the Brazilian State in the favelas of Rio de Janeiro, as part of a public safety action based on repression / territorial pacification - that in many ways, especially the structural, relate to Medellin. Keywords: Urban Violence, Medellin, Pacification, Rio de Janeiro.

\footnotetext{
${ }^{1}$ Doutora em Conservação e Restauro pela Universidade Federal da Bahia (UFBA). Professora regular em regime de dedicação exclusiva da Faculdade de Arquitetura da Ufba e vice coordenadora da Residência em Arquitetura, Urbanismo e Engenharia do Programa de Pós-graduação em Arquitetura e Urbanismo da UFBA. E-mail: anyivo@gmail.com

2 Doutor em Arquitetura pela Universidade de Roma (1964). Integra o quadro docente permanente do Programa de Pós-graduação em Arquitetura e Urbanismo da UFBA.

E-mail: pasqualinomagnavita@terra.com.br
} 
A cidade de Medellín (Colômbia), até pouco tempo considerada capital mundial das drogas, hoje é apresentada como modelo de intervenção urbana eficaz para a pacificação de áreas antes controladas pelo tráfico de drogas. Como urbanistas e arquitetos da cidade, ao visitar Medellín, indagamos sobre os significados dessas intervenções urbanas realizadas nas comunas e apresentadas ao mundo como modelo exitoso de projetos de transformações do urbano. E mais, indagamos: Em que medida é possível traçar nexos entre o modelo de Medellín e as intervenções em outras cidades, a exemplo da pacificação do Complexo do Alemão no Rio de Janeiro (Brasil)?

São essas as questões que irão nortear este texto, que faz da descrição das visitas realizadas a Medellín e das percepções por elas suscitadas seu objeto de análise ${ }^{3}$. O texto irá refletir sobre algumas intervenções e projetos visitados nessa cidade, apresentados mundialmente como ícones de um novo tempo, e, num segundo momento, estabelecer nexos com as recentes intervenções urbanísticas realizadas no Morro do Alemão, na cidade do Rio de Janeiro.

Pinçar uma cidade das mais violentas do mundo da pobreza e do tráfico de drogas e tornála um exemplo de recuperação para o mundo inteiro, para além das funções urbanísticas materiais e inclusivas, constitui uma experiência reforçadora de um marketing de cidade e afirma a possibilidade, no nível da formação subjetiva da população da e na cidade, de transformar as cidades em espaços pacificados. Sob a égide do capital, verifica-se a existência de uma multiplicidade incomensurável e uma patente heterogeneidade de cidades violentas no mundo, muitas das quais, agora, na era informacional e sob a égide das "Sociedades de Controles", buscam se afirmar como imagens e espetáculos atraentes, mediante construções simbólicas midiáticas que as configuram como redutos "pacificados".

A história de Medellín, segunda cidade mais importante da Colômbia, é marcada por "guerra e paz". Nos anos 80, a "aparente 'paz' urbana, mantida através de estratégias de controle e repressão da dissidência política nas cidades, foi rompida pela guerra declarada pelas autoridades de segurança aos narcotraficantes." (COSTA; RAMÍREZ, 2012: 118).

A indústria da droga se consolidou como vetor econômico e político no campo e na cidade, desenhando e redesenhando as dinâmicas urbanas da década de 80 em Medellín - quer seja pela população expulsa do campo, que migrou para cidade, quer seja pelas oportunidades de negócios relacionados à economia da droga. No final dos anos 80 e início dos anos 90, com a desarticulação do cartel de Medellín, os grupos do narcotráfico se aproximam dos grupos em confronto armado no campo, originando as milícias urbanas. É nesse contexto que o Estado reage de forma

3 Os autores deste texto visitaram Medellín em 2009 e em 2014. 
repressora e, ao mesmo tempo, com compensações sociais, visando a reduzir a influência miliciana sobre os bolsões de pobreza.

A urbanização do confronto armado fez com que as forças de segurança da cidade redefinissem a "guerra" a partir da necessidade de impedir a contaminação da cidade pela barbárie do campo. Tal movimento autorizou a intensificação da violência contra as áreas mais pobres da cidade. (COSTA; RAMÍREZ, 2012: 120).

Esse cenário foi propício ao surgimento de forças paramilitares, incluindo empresas de segurança privada na cidade, o que representou a apresentação e a legitimação estatal de novos agentes da violência na cidade, que atuavam de forma repressora sobre os mais pobres:

Assim, modificava-se na segunda metade da década de 1990 a apresentação dos atores violentos em Medellín, mas não as bases de sustentação da violência. Ou seja, a violência continuava refletindo os mesmos rostos e experiências, mas o rótulo mudou. Agora os delinquentes e subversivos passavam a contrainsurgentes e colaboradores das forças de segurança pública. (COSTA; RAMÍREZ, 2012: 120).

Seguindo a lógica de compensações sociais, as obras urbanísticas nas áreas mais pobres da cidade foram implementadas no final dos anos 90 e no início dos anos 2000, posteriormente ao controle estatal, mediante a militarização desses territórios, cujo expoente é representado atuação militar violenta da "Operação Orión" ${ }^{4}$, considerada um rito de passagem para um "novo tempo".

Ou seja, as violências da "guerra" em Medellín não se esgotam na expulsão e no extermínio dos inimigos, nem tampouco no domínio dos territórios. Tais violências antecedem e sucedem a experiência dos homens armados em combate. (COSTA; RAMÍREZ, 2012:123)

Não obstante os avanços obtidos no enfrentamento da violência, numericamente medidos e mundialmente reconhecidos, a qualidade construtiva e o decoro desses equipamentos públicos, símbolos de um novo tempo, buscam "costurar" uma cidade ainda segmentada e marcada pela desigualdade social materializada no espaço construído.

En el territorio complejo y fracturado de Medellín, se ha tendido una nueva red de programas sociales, edificios, espacios y sistemas de transporte público que ha logrado que la ciudadanía se reencuentre. (ECHEVERRI, 2014:223)

As construções simbólicas relacionadas no campo do urbanismo tratam fundamentalmente essas intervenções como exemplos virtuosos e positivos de mudança social e de enfrentamento do tráfico de drogas, mediante a materialização da presença estatal com obras de mobilidade e de edifícios para cultura e educação. No entanto, anula-se o tratamento acerca da luta ideológica

\footnotetext{
${ }^{4}$ Operação militar violenta de grande vulto, para retomada do domínio sobre a Comuna 13, expulsando as milícias guerrilheiras. Os atores armados se mantiveram no território como garantia à pacificação territorial (COSTA; RAMÍREZ, 2012).
} 
entre duas concepções distintas de produção das e nas cidades, ou seja, aquela orientada estrategicamente para o mercado, o lucro do capital, a privatização dos bens materiais e bens imateriais, de um lado, e outro modelo em que prevalece o ideal de socialização dos bens públicos como direito e fundamento da cidadania. Ambos, paradoxalmente, constituem potenciais meios de controle. É essa última perspectiva que o texto elege como fio condutor, permitindo articular as intervenções no urbano de Medellín com as intervenções no Morro do Alemão, no Rio de Janeiro.

Sem dúvida, as intervenções urbanas na cidade de Medellín representam ganhos significativos para a cidadania, mas constituem também uma experiência de sucesso de um marketing empresarial aplicado às cidades em escala mundial.

Essas intervenções tornam-se "referenciais dos projetos de transformação do urbano" e avançam como ações constituintes de uma dinâmica de cidade inserida em uma política de segurança mundialmente divulgada e reconhecida como exemplar - "a aparência física da cidade como expressão física de mudanças", como aquilo que reifica outra visão e outra realidade: a "Medellín ciudad para la vida" e as altas taxas de mortalidade que marcam e reescrevem sua história.

Los distintos reconocimientos que Medellín ha recibido recientemente, entre los que se encuentran: La Ciudad más Innovadora del Mundo (2013), Ciudad Resiliente - entre las cien más destacadas del mundo (2013) - y el Premio Internacional de Diseño y Arquitectura (2013) exaltan justamente los atributos que hoy el mundo observa em Medellín y la constituyen en un laboratorio en los temas de ciudad. (CARTA Medellín, 2014)

Com essa perspectiva, esse esforço de análise crítica toma como objeto os projetos urbanos nas comunas em Medellín, especialmente as obras de mobilidade urbana, a criação de espaços públicos e de lazer e os espaços educativos, projetos difundidos mundialmente. O nosso "olhar estrangeiro" diante desse universo é assumido como leme para as análises. De um lado, ele contém possíveis limitações pela própria estranheza dos visitantes e a pouca intimidade com o local e com os processos de desenvolvimento desses projetos. Por outro, essa própria condição de estrangeiro abre a possibilidade de liberdade e criação de novas instâncias analíticas sobre esse objeto, as quais, nos parece, merecem esse registro.

Os riscos da proposta são assumidos, mas - tendo em vista as recentes intervenções do Estado brasileiro nas favelas do Rio de Janeiro e em implantação em outras cidades do Brasil, como partes de uma ação de segurança pública baseada na repressão, no controle e na pacificação territorial - o texto pode contribuir servindo como referência para uma análise crítica também do 
modelo que vem sendo adotado no Brasil, que se relaciona com a experiência de Medellín em diversos aspectos, especialmente aqueles relacionados a determinações mais estruturais.

\section{VISITA À COMUNA 13 E À COMUNA 01 EM 2014}

No ano de 2014, ocorreu o Fórum Mundial de Urbanismo em Medellín, Colômbia. A magnitude do evento se evidenciou não só pelo número de visitantes, mas também pela presença de chefes de Estados, técnicos e pensadores renomados. O interesse pelo modelo de Medellín se expressou na disputada audiência para assistir à palestra do então prefeito dessa cidade. Em pleno Fórum Mundial de Urbanismo de 2014, os gestores, participantes e os arquitetos-urbanistas conheceram os projetos de reestruturação urbana na cidade, reconhecidos mundialmente como exemplares na transformação de cidades segmentadas.

A visita foi organizada por uma empresa de turismo local, ao preço de 40 dólares por pessoa, para conhecer a Comuna 13. Na hora marcada, todos os estrangeiros, majoritariamente arquitetos, estavam a postos para a aguardada visita. A primeira surpresa foi a companhia de dois policiais armados durante a visita. A pequena Van cortou a cidade e, em dado momento, iniciou a subida. A paisagem foi gradativamente se transformando: de uma ocupação territorial regular, estruturada em quadras, para uma ocupação irregular, densa e de edificações frágeis, "orgânicas", informais, implantadas em uma topografia acidentada.

Desde os primeiros sinais de mudança no ordenamento territorial percebem-se também as primeiras intervenções de requalificação do urbano: um corrimão, uma passarela, um pequeno estar público, pequenas áreas verdes etc. A continuidade dessas pequenas ações transformavam o espaço, dando maior qualidade e melhores condições de uso e de acessibilidade ao lugar.

Em determinado momento, a Van parou, e o grupo foi convidado a descer e a andar pela área, acompanhado dos policiais. Num primeiro momento, a paisagem encontrada pouco se distingue da existente nos bairros populares das cidades brasileiras, mas, passada a primeira impressão, percebem-se particularidades, como o número de andares (em sua maioria dois, térreo mais um pavimento), a ausência de lajes de cobertura no terraço, que lá são substituídas por coberturas em telha de fibrocimento seguras por pedras. Poucas pessoas transitavam nas ruas. Também surpreende o baixo numero de pequenos comércios.

A topografia mais íngreme possibilitava a visão da vastidão desse território. No meio do morro, uma via com larga balaustrada, como um invólucro, serve de elemento de articulação a qualquer ponto da Comuna, assim como permite o domínio da paisagem (Figura 01). Nesse grande 
anel, como elemento de articulação, localizam-se escadas, escorregadores, rampas e estruturas de ligação com as mais diversas formas e desenhos, que servem ainda como pequenas arenas e pontos de encontro. Os telhados de telha plana, com suas pedras de sustentação devido aos ventos fortes e pinturas com os mais diversos temas, chamavam a atenção pelo colorido do conjunto. As cores constituem instrumento importante da ação transformadora, dando "vida" às fachadas e coberturas. Os escassos e reduzidos largos tornam-se pequenos espaços de convívio, com banquetas coloridas. Escorregadores e plataformas desniveladas transformam o subir e descer dos difíceis acessos em brincadeiras infantis. Destacam-se, na densa ocupação, algumas quadras esportivas devidamente cercadas e iluminadas.

No meio desse anel, está localizada a escada rolante pública, elemento marcante da intervenção, ligada a um pequeno centro de venda de artesanato produzido por moradores locais, assim como de souvenirs de Medellín, que estampam alguns projetos urbanos da cidade. Essa escada conduz a uma rotatória possível de ser acessada de carro sem maiores esforços.

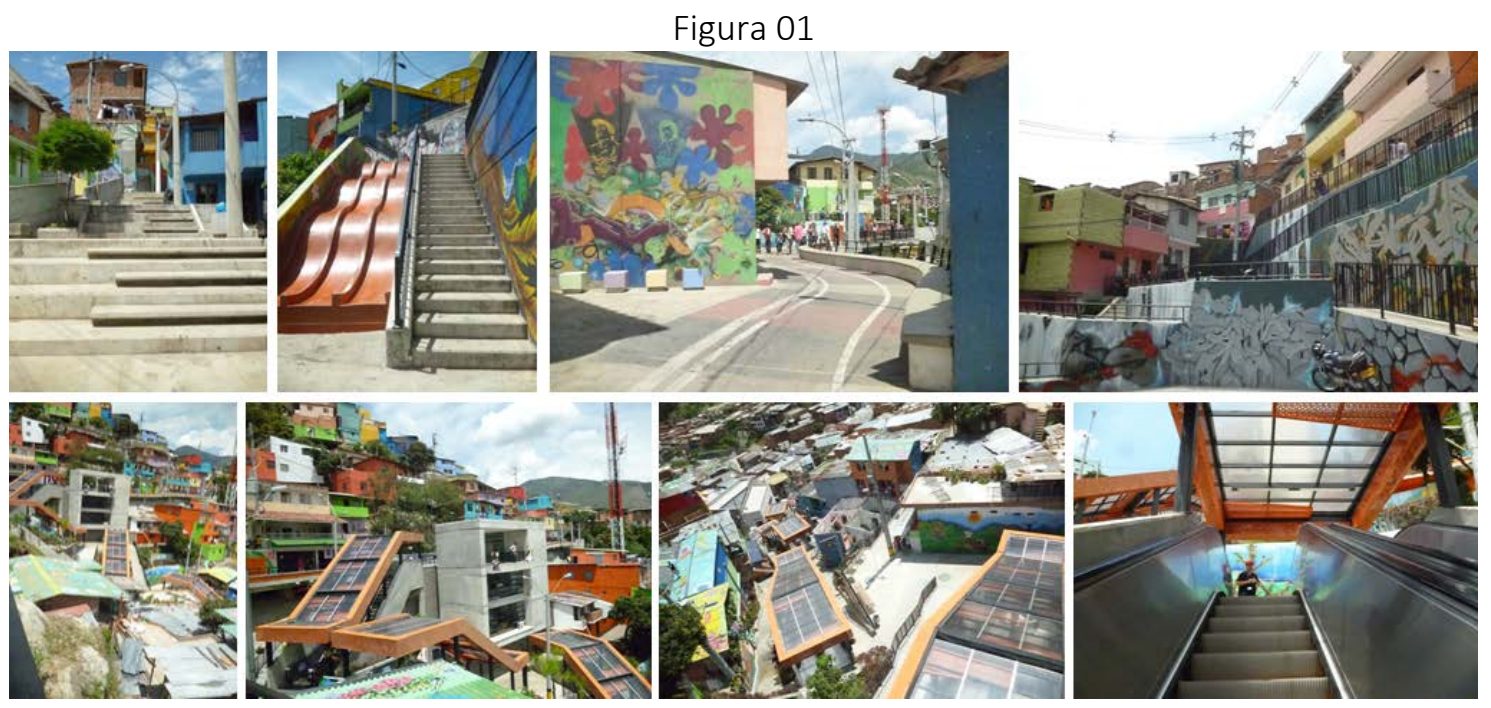

Fotos: Any Ivo, 2014

Essa grande escada rolante constitui elemento central do projeto, encantando os olhos dos visitantes, pela adequação e decoro do que se apresenta como arquitetura. A descida pela escada rolante, uma novidade aos olhos estrangeiros, supera as expectativas, brindando as visitas com música erudita - naquele momento, a opera "Os Miseráveis". Após a descida, as paredes da rotatória contam, na linguagem das ruas - o grafite -, a história local: de um período escuro e sombrio a um estágio claro, cheio de luz e cores. A limpeza é outro item observado. 
No retorno, o grupo conheceu uma das bibliotecas públicas integrantes da ação estatal, que se apresenta como 'o estado de educação' (Figura 02). Trata-se de um prédio localizado ao alto, com arquitetura diferenciada e de qualidade, incorporando a transparência e a valorização cidadã na arquitetura. Edifício implantado em níveis, com amplo acesso em escadaria - uma arena - que permite, pela transparência dos parcos panos de vidro que definem as áreas, vislumbrar quase todo o ambiente. Com isso, valoriza-se o cidadão que passa a controlar inclusive as áreas administrativas e de trabalhos internos e vice-versa.

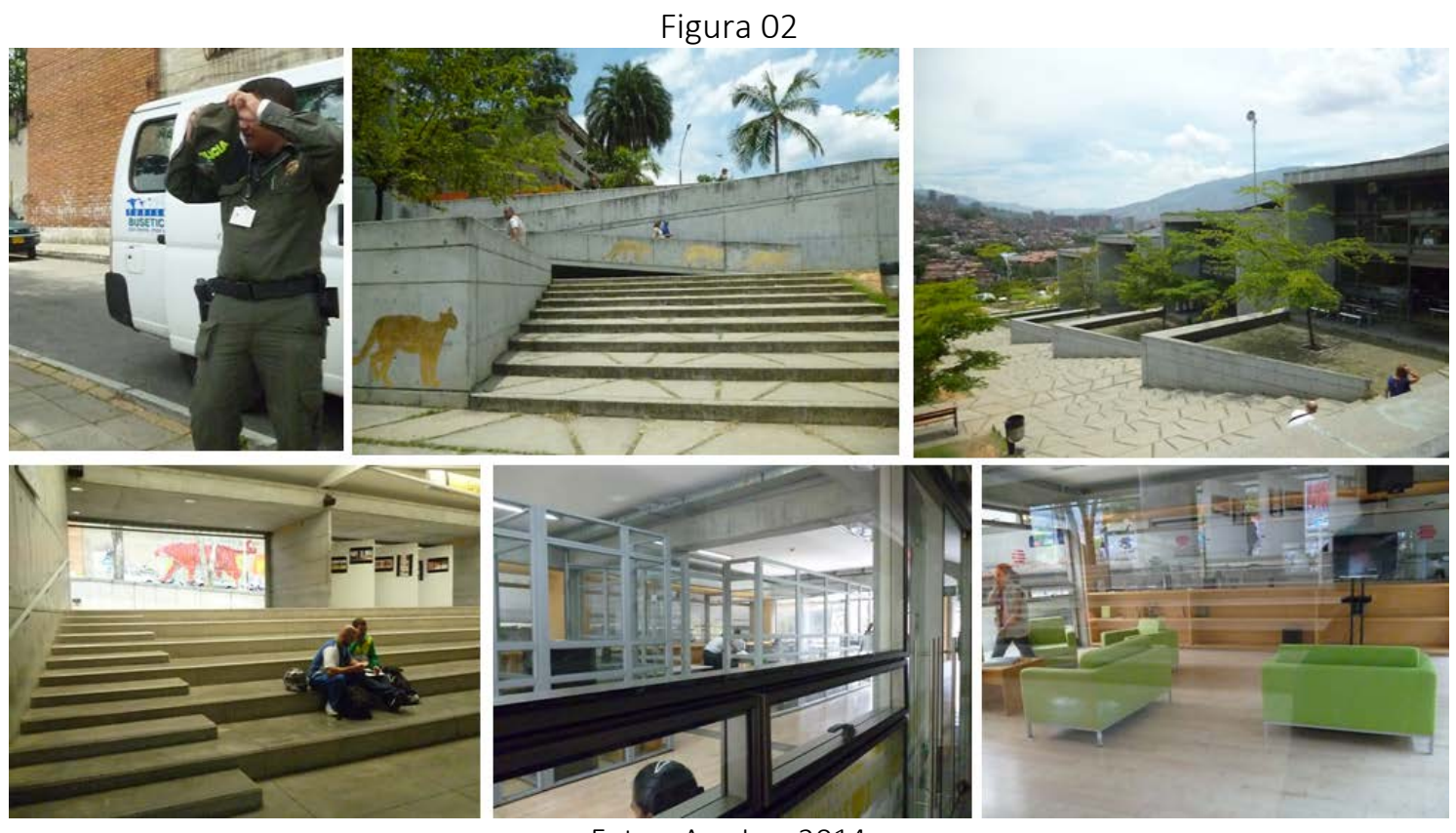

Fotos: Any Ivo, 2014

A ida à Comuna 01 (Figura 03) - onde se localiza a famosa Biblioteca de Espanha - serviu para experimentar a "cultura do metrô", apresentada pela guia como uma mudança de práticas e das relações familiares. Segundo essa perspectiva, ao reduzir o tempo de deslocamento, o metrô possibilita que os pais tenham mais tempo em família e com seus filhos.

Para cumprir o trajeto - do Fórum até a Comuna 01 -, usamos inicialmente o $B R T^{5}$, em seguida o metrô e, posteriormente, seguimos pelo teleférico, passando ao lado da famosa biblioteca de Espanha, à época, em reforma. Sem dúvida, as estações do teleférico, no dia a dia, contribuem para conforto e facilidade de locomoção dos moradores, dando sempre a condição de descida.

${ }^{5}$ Bus Rapid Transit (BRT) consiste num sistema de transporte publico baseado em vias exclusivas para ônibus, de tráfego rápido. 

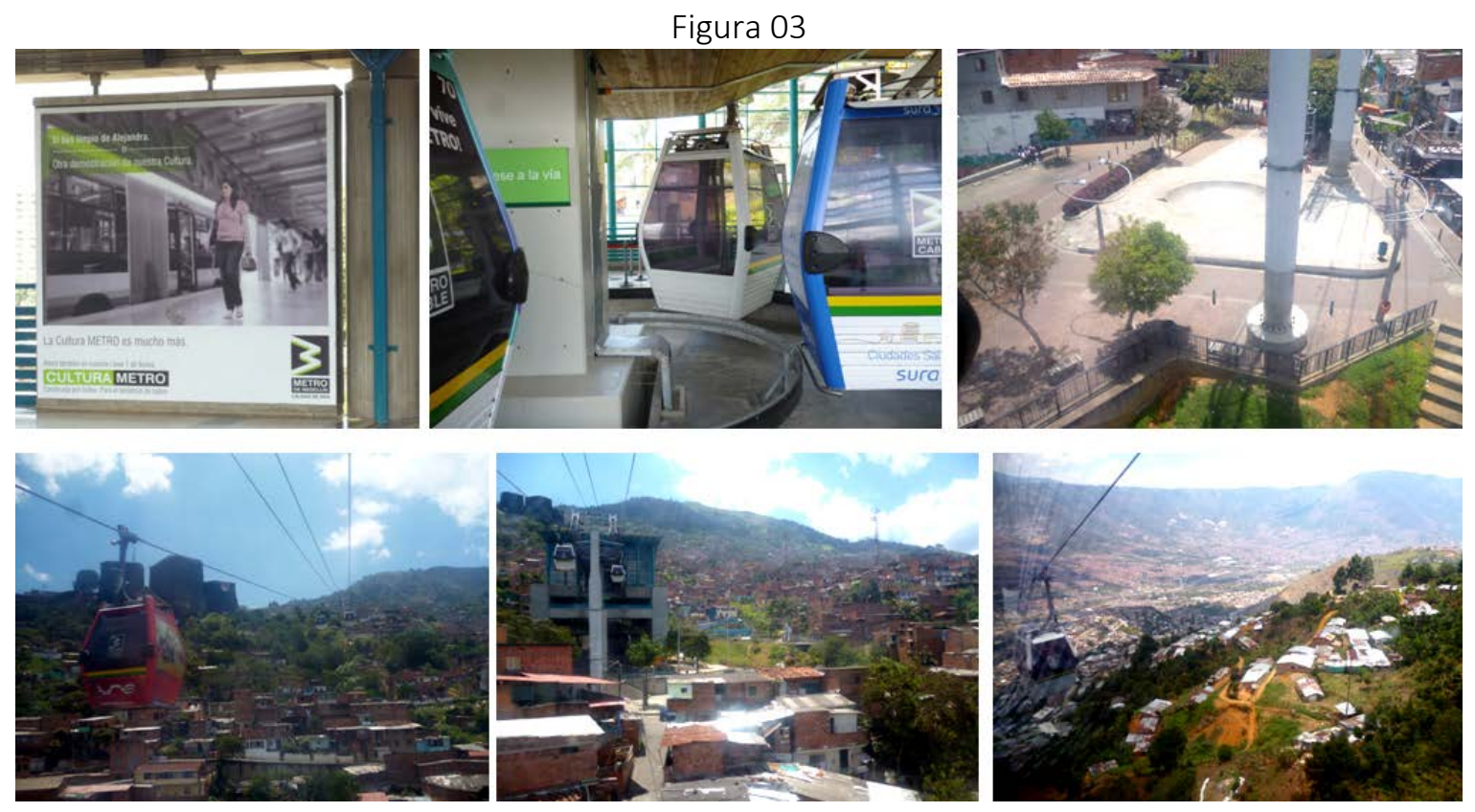

Foto: Any Ivo, 2014.

Passar sobre a Comuna 01 dá uma ideia da magnitude da pobreza. A urbanização, sem dúvida, reduz a precariedade e a perversidade materializada na forma de habitar. À medida que o teleférico seguia, afastávamos da cidade e, gradativamente, o que é urbano se diluía e se espaçava. A fragilidade das construções aumenta em áreas de topografia extrema: resquício de um tempo passado ou evidencias do tempo presente e prenúncio do futuro? Como um grande cinturão verde, um parque devidamente cercado delimita a área de expansão que, juntamente com a topografia quase vertical, praticamente bloqueia a expansão territorial das comunas.

Inegavelmente, há qualidade construtiva e de projeto nesses equipamentos públicos. Esses cenários, juntamente com a ampla publicidade, encantam, com um "canto de sereia" ${ }^{6}$, o estrangeiro, que se deixa envolver com o desenho apresentado como transformador da cidade. Esse encantamento se justifica quer pela perversão da realidade das cidades na America Latina, quer pela expectativa criada pelas publicações sobre a área, que enaltecem esses projetos pela eficiência e qualidade de seus equipamentos.

De fato, ficamos admirados, como uma cidade de porte médio, uma das mais violentas do mundo, sob o controle do tráfico de drogas, passou, em um tempo relativamente curto, a ser um acontecimento mundial de transformação urbana. A qualidade dos projetos e construtivas marcam essas intervenções urbanas e surpreende o visitante. Mas, o que é apresentado como intervenções

\footnotetext{
${ }^{6}$ Usamos a expressão "canto da sereia" como sinônimo de sedução ilusória, atraente, capaz de obscurecer a razão e a capacidade de discernimento.
} 
urbanísticas manifesta não apenas a relação entre técnica e estética, mas principalmente, a relação entre política e economia. Considerando que nos encontramos, hoje, no âmbito das "sociedades de controle", cabe lembrar esse entendimento deleuzeano:

... o capitalismo manteve como constante a extrema miséria de três quartos da humanidade, pobres demais para a dívida, numeroso demais para o confinamento: o controle social não só terá que enfrentar a dissipação de fronteiras, mas também a explosão dos guetos e favelas. (DELEUZE, 2000:224)

A experiência pacificadora, em Medellín, tem uma repercussão midiática enorme. Não podemos deixar de reconhecer a redução da violência medida em números: em 1991, um pouco antes da morte de Paulo Escobar (Chefão da droga) - marca histórica dessa transformação - o número de assassinatos situava-se em torno de 6.000, e, em 2012, caiu para 1.247, tendo a cidade recebido o prêmio da ONG americana Urban Land Institut. No entanto, estudos ${ }^{7}$ mostram que, em 2013, a Colômbia ainda ocupava a quinta posição entre os países que mais matam jovens, com uma taxa de 70,5, figurando em terceiro lugar em número de homicídios, com uma taxa de 45.

Esse "canto de sereia" impõe um esforço analítico adicional para tentar entender além do que é apresentado oficialmente. Entretanto, o que mais poderíamos analisar nessas visitas guiadas durante o Fórum Mundial de Urbanismo? E de qual "eficiência" se trata quando se fala dessas intervenções? Quando nos focamos sobre um ponto, em geral, não percebemos devidamente a superfície onde ele se encontra. Assim, quando se foca sobre Medellín e seus resultados exitosos na guerra contra o tráfico de drogas, não somos apresentados à Colômbia como nação, à América como continente e, ainda menos, ao resto do planeta. Assim, o esforço para apreender os sentidos do local impõe o exercício de apreender a complexidade dos empreendimentos em análise, tanto do ponto de vista dos moradores, como do ponto e vista das estratégias da política e do marketing de cidades como processos sutis de formação do consenso e de disciplinamento das subjetividades.

Assim, buscando entender essas intervenções do ponto de vista da dinâmica e da prática localizada dos moradores, podemos sugerir que as pequenas áreas de convívio, com bancos individualizados, pouca vegetação de médio e grande porte, favorecem muito mais o fluxo do que a permanência contínua e o encontro. O uso da transparência incorporada como solução arquitetônica que possibilita ao cidadão um amplo acesso visual aos espaços do edifício, rompendo

\footnotetext{
${ }^{7}$ Segundo Sobral (2013), a taxa de 54,7 de homicídios de jovens coloca o Brasil na sétima posição no âmbito mundial, posição mantida, considerando-se a taxa de 27,4 para homicídios. Em primeiro lugar está El Salvador.
} 
barreiras e facilitando a regulação simbólica dos serviços públicos pela sociedade civil, torna-se, ao mesmo tempo, um pan-óptico controlador dos usuários locais, o que, associado à presença de guardas armados e detectores de metal altera o primeiro sentido encantador da obra.

O referido anel da Comuna 13, além de servir à mobilidade, fornece visão privilegiada do território, podendo significar, em momentos de crise e conflitos, vantagem estratégica de acesso e controle sobre a vastidão de casas pobres e frágeis. Nelas, a individualização dos tetos pintados com diferentes cores e desenhos, com a consequente facilidade de identificação, tem um valor instrumental e estratégico de controle, potencializando as estratégias pan-ópticas de vigilância dos espaços, sob essa perspectiva entendidos como potenciais para o crime.

O teleférico e suas estações elevadas (Comuna 01, Figura 03), seguindo essa outra percepção, não comumente explicitada na difusão e análise desses projetos, são também estruturas de monitoramento constante, possibilitando uma visão privilegiada do território. As quadras, num outro sentido, encontram-se articuladas a equipamentos públicos de maior destaque e de mobilidade e podem, eventualmente, servir como parada de helicópteros e chegada de outros equipamentos de combate de maior poder ofensivo, em pontos estratégicos de fortaleza e controle, evidenciando outra possível razão urbanística dessas intervenções.

\section{SOBRE A VIOLÊNCIA SIMBÓLICA E O DIREITO PENAL DO INIMIGO NO URBANO}

Esse processo de conversão do espaço físico via processos de requalificação e intervenção urbana encontra paralelo no que Bourdieu (1989) chama de violência simbólica ${ }^{8}$. Esse processo associado à noção foucaultiana de sociedade disciplinar ${ }^{9}$, que se amplia sobre os territórios urbanos da pobreza -, aliado às máquinas de sedução ou persuasão ${ }^{10}$ e suas novas formas de

\footnotetext{
${ }^{8}$ Aquela exercida pelo uso dos símbolos e signos culturais que contribuem para a reprodução de dominações não declaradas e não percebidas como violência, mas reconhecidas como autoridade natural.

${ }^{9}$ Pode-se, então, falar, em suma, da formação de uma sociedade disciplinar nesse movimento que vai das disciplinas fechadas exercidas em espaços confinados, espécie de "quarentena" social, até o mecanismo indefinidamente generalizável do "pan-optismo", ou seja, a dominação dos corpos e das ações e a relação com os espaços fechados, com a função de disciplinar os sujeitos; tais conceitos são estudados e analisados por Foucault (2010). São os corpos dóceis que se apresentam como reflexo dessas formas de moldagem, nas quais a estrutura espacial se torna um elemento de formação das ações e comportamentos.

${ }^{10}$ Foucault (2008) investiga as relações de poder, invertendo os parâmetros e as hierarquias característicos da filosofia política tradicional, ou seja, colocando em suspenso as análises sobre as formas como o discurso da verdade limita e fixa o direito do poder. Em lugar de um poder absoluto e centralizado, reconhece a multiplicidade de poderes característicos e constituintes do corpo social. São as formas múltiplas de dominação e sujeição que interessam: debruça-se sobre os formatos menos óbvios do poder soberano central, buscando captar o poder "nas extremidades, em suas últimas ramificações, lá onde ele se torna capilar." (FOUCAULT, 2008:182). É nesse sentido - como poder que busca a dominação das mentes nos
} 
dominação, mediante o controle dos processos de subjetivação, caracterizam as sociedades de controle (DELEUZE, 2000) e são as noções que orientam este esforço de entendimento sobre as intervenções e o tratamento simbólico de imagens de melhorias urbanas nas transformações realizadas em Medellín.

Essa concepção pan-óptica sobre os bolsões de pobreza, transformando a "segurança humana" em discurso, tem como camada subterrânea a tese do Direito Penal do Inimigo, desenvolvida por Jakobs (2007 [1985]). O autor defende que o "ilícito" rompe o contrato social, permitindo e "obrigando" que a relação do Estado mude. O grupo que atua de forma ilícita é visto num contexto de guerra como o "inimigo", como real ameaça à ordem social e política. Esse quadro e a concepção de "inimigo" trazem mudanças significativas sobre a natureza da relação e da atuação do Estado, que age diferentemente do agir segundo o direito penal cidadão - aquele que, em tese, reconhece os direitos da pessoa e pune o ilícito. Jakobs (2007 [1985]) estrutura sua tese sobre o "direito penal do inimigo" em quatro eixos: punição antecipada, penas desproporcionais, relativismo dos direitos e leis especiais para determinados grupos. O indivíduo ameaçador torna-se despossuído de direitos, e a certeza de que o crime será realizado antecipa a punição. Com isso, justifica-se a ação de punir antecipadamente como prevenção ao "futuro certo do crime". A punição avança baseada na probabilidade de o agente vir a cometer um crime, e a pena se fundamenta em atos futuros, não na sanção a fatos cometidos. Assim, a probabilidade do crime se torna o próprio crime. Essa perspectiva, que dialoga diretamente com as obras de Hobbes e Fichter, considera a rebeldia uma traição ao Estado e, num outro sentido, reconhece que a morte civil torna-se base para a construção de um contrato penitencial em lugar do contrato social.

Com isso, podemos, então, sugerir que esses bolsões de pobreza histórica, territorialmente segmentados e consolidados nas cidades, são, num primeiro momento, territórios daquilo que Hobbes chama de "estado de natureza", e, por fim, constituem potenciais históricos da criação de contestação ao Estado e à ordem vigente. Entretanto, como são reconhecidos como caóticos e fora de ordem, isso legitima a prática da violência física do Estado. Configuram, ainda, estados de exceção (AGAMBEM, 2004) e, assim, a "custódia de segurança antecipada" é exercida territorialmente sobre todos aqueles que moram nessas áreas, independentemente de participarem ou não do "estado comunitário-legal". Dessa forma, "os meios justificam os fins"

processos de subjetivação individual e coletiva e, para isso, contribuem decisivamente os processos midiáticos da informação e comunicação das tecnologias avançadas em espaços abertos e que agora modulam, e não apenas modelam, os sujeitos - que as atuais estratégias de mercado fundadas na gestão de imagens estão sendo aqui analisadas. 
(Maquiavel), e os danos sobre as vidas dos cidadãos são mensurados como "perdas" necessárias ao bem comum e coletivo no enfrentamento do suposto "inimigo".

Mas de que "inimigos" estamos tratando? Das camadas populares como ameaça real à ordem social e política? Isso não seria novidade na história do urbanismo e para a concepção do urbano que segue uma lógica de militarização nas cidades. Numa reflexão mais profunda, podemos associar o destaque de Medellín não apenas ao combate do tráfico de drogas, à repressão das camadas populares em condições de pobreza e ao expurgo humano. A grande maioria das cidades da América Latina (para não falar da África e de outros países pelo mundo afora) se caracteriza por suas favelas, ou seja, extensões incomensuráveis de áreas habitadas por excluídos, áreas marcadas pela ausência de serviços básicos e estigmatizadas pela violência gerada pelo próprio modo de produção do capitalismo, a violência "sistêmica" (ZIZEK, 2014). Tal quadro é apresentado como uma não violência, um estado de coisas "normal" e pacífico, hoje em seu "estágio informacional", característico das "sociedades de controle". A perversidade desse sistema de produção, representada, na cidade, pelos bolsões de pobreza estrutural, encarna aquilo que Benjamin ([1920], 2011) chama de "violência divina", a qual, como signo das injustiças, cabe nos eventos do mundo. Nesse cenário, o tráfico de drogas não é apenas uma causa, mas também uma das consequências dessa ordem.

Quem conhece a história da Colômbia, nas últimas décadas do século XX, acaba entendendo que a "guerra" contra o narcotráfico, travada nesse país, pode expressar uma extensão "periférica" da polarização entre direita versus esquerda, expressa numa configuração do pensamento do senso comum maniqueísta, marcado pelo bem e o mal, a paz e a guerra, ou, ainda, de entidades pacificadoras virtuosas contra o "crime organizado".

Com o fim da Guerra Fria, a partir dos anos 80, o discurso de defesa dos Estados Unidos se orienta, prioritariamente, para o combate ao tráfico de drogas. ${ }^{11} \mathrm{~A}$ redução da oferta é eleita como princípio dessa atuação, ou seja, o combate aos polos produtores é a diretriz que tem como consequência a atuação dos Estados Unidos em território estrangeiro, com especial atenção para a região andina - Bolívia, Colômbia e Peru. Segundo Guzzi (2008), é parte dessa política a criação do "Plano Colômbia", que se apresenta com o objetivo de desenvolvimento econômico e social, mas, na prática, essa política se expressa eminentemente pela militarização no enfrentamento dos movimentos guerrilheiros nesse país.

\footnotetext{
${ }^{11}$ Os Estados Unidos, no combate às drogas, passam de um investimento de US\$ 3 bilhões no ano fiscal de 1982, para um montante de aproximadamente US\$ 9 bilhões no ano fiscal de 1989 (GUZZI 2008).
} 
Segundo Pires (2014), desde 1999, o governo colombiano recebeu oito bilhões de dólares dos Estados Unidos para aquisição de helicópteros e treinamento militar. O exército colombiano é o maior da América Latina, sendo o segundo do Continente Americano - na primeira posição estão os Estados Unidos. Ainda segundo esse autor, $5 \%$ a $6 \%$ do PIB da Colômbia foi direcionado, em 2010, para defesa, valor muito superior ao montante investido em educação, que não chegou a $1 \%$ do PIB em 2008 (PRESIDENTE... 2008).

Apesar de os anos 2000, após os atentados de 11 de setembro, serem marcados por uma política externa dos Estados Unidos direcionada ao combate da produção de armas e ao terrorismo, como observa Guzzi (2008), o estreitamento da cooperação com a Colômbia, que assume internamente a "linha dura" de combate aos movimentos guerrilheiros mediante o combate à indústria da droga, é uma marca desse novo tempo. Essa atuação é justificada como fortalecimento das instituições democráticas, combate às drogas, desenvolvimento socioeconômico e assistencialismo humanitário, bem como uma política de combate às armas e ao terrorismo em âmbito mundial.

Os altos investimentos militares dos Estados Unidos não se limitaram ao fornecimento de armamentos de última geração, mas incluíram, também, treinamento de militares colombianos no referido país, num envolvimento estratégico com a Colômbia. ${ }^{12}$ Assim, as intervenções urbanas nas comunas de Medellín extrapolam a questão da urbanização e do combate à violência urbana e à droga criminalizada, e se articulam também a interesses econômicos e geopolíticos mundiais: a Colômbia está entre os quatro maiores fornecedores de recursos energéticos para os Estados Unidos - recursos hidroelétricos e produção eólica de energia, assim como grandes reservas de petróleo -, constituindo uma das maiores reservas ecológicas do mundo. Além dos interesses econômicos, podemos relacionar as obras urbanísticas em Medellín, pelo exposto, com as estratégias de controle dos territórios.

A experiência pacificadora em Medellín, de uma outra perspectiva, de dominação consensual, tem um impacto simbólico enorme, embora os números ainda não caracterizem a eliminação do tráfico de drogas. Tampouco os números refletem a imagem mundialmente divulgada da "Antioquia la más educada":

Conscientes de que los políticos toman las decisiones más importantes de una sociedad y de que en el país la educación no ha sido una preocupación principal por causa de los violentos, los ilegales y los corruptos, hace 15 años

\footnotetext{
12 Vale destacar a Convenção de Viena (1988), a Cúpula de Cartagena (1990) e de San Antonio (1992), assim como a "Estratégia Andina" criada pelo governo Bush.
} 
iniciamos en Medellín nuestro movimiento Compromiso Ciudadano y decidimos trabajar por la educación como motor de la transformación. Hoy Antioquia la más educada es la expresión que identifica nuestro plan de desarrollo. Es la concreción de nuestro proyecto político. (VALDERRAMA, 2015)

Essa construção simbólica positiva da pacificação guarda infindas formas de violência, dentre as quais, vale destacar: encobrir pelo "canto da sereia" a possível natureza repressora e de controle territorial desses projetos e, num sentido mais amplo, neutralizar, no âmbito do imaginário, em escala mundial, as possíveis ações contrárias à geopolítica vigente.

\section{MEDELLÍN COMO MODELO PARA AS AÇÕES NO COMPLEXO DO ALEMÃO}

O Anuário Brasileiro de Segurança Pública de 2014 ilustra o estado epidemiológico da violência em algumas cidades brasileiras. A cada 10 minutos uma pessoa é morta no Brasil, o que totalizou 53.646 homicídios nesse ano. Em um ano, a polícia brasileira tirou a vida de 11.197 cidadãos. ${ }^{13}$ Observadas as características sociodemográficas dessas vítimas, 30,5\% são negros e 93\% são homens. O equivalente a 1,26\% do PIB foi gasto em segurança pública ${ }^{14}$, obtendo-se um número absoluto de homicídios da ordem de 50.806 mortes. Somando os gastos com violência, segurança pública, prisões e unidades socioeducativas, atingimos 5,4\% do PIB brasileiro, significando 258 bilhões de reais gastos em "segurança".

Entre as 50 cidades mais violentas do mundo, 41 estão na America Latina; delas, 5 estão localizadas na Colômbia e 19 são brasileiras. Medellín passou da décima posição em 2010 a ocupar a posição 35 em 2013 e, no ano do Fórum Mundial Urbano, em 2014, passou para a posição 49. Surpreendentemente, a capital fluminense não aparece no estudo. Salvador ocupa a décima sétima posição e Maceió é a quinta cidade mais violenta do mundo, segundo esse estudo.

Nesse contexto endêmico de violência, o modelo de transformação de Medellín é apresentado como fonte inspiradora para as ações e intervenções urbanísticas no Complexo do Alemão, no Rio de Janeiro. Composta por treze comunidades ${ }^{15}$, essa área foi reconhecida pelo

\footnotetext{
${ }^{13} \mathrm{O}$ que corresponde ao total de mortes cometidas pela polícia americana em 60 anos de atuação.

${ }^{14}$ Os 27 países da União Europeia, juntos, gastaram em segurança pública 1,30\% do PIB, nesse mesmo período, com uma taxa de homicídio de 1,1.

15 Apesar de haver oscilações na definição do número de comunidades que compõem o Complexo do Alemão, assim como do número de moradores, adotamos como referencial, neste trabalho, o número de Associações de Moradores desse complexo: Casinhas, Fazendinha, Grota, Itararé/Alvorada, Matinha, Morro da Baiana, Morro da Esperança, Morro do Adeus, Morro do Alemão, Morro dos Mineiros, Nova Brasília, Palmeiras e Reservatório de Ramos.
} 
Estado como lócus do "poder paralelo" - exercido pelo Comando Vermelho. Desde 2007"16, esse território vem detendo a atenção dos poderes públicos de segurança, sendo foco de ações de combate ao tráfico de drogas, com a participação de diversas instâncias de governo.

Tal contexto tem como resultado a militarização desse território até os dias atuais, num processo marcado, desde o início, por questionamentos e polêmicas sobre uma forma de ação e intervenção que submete a comunidade a atos violentos e arbitrariedades, significando um permanente estado de "conflito armado". ${ }^{17}$ Dessa perspectiva, significa um retrocesso na construção de cidadania e na formação do estado de direito. "Desta forma o Estado brasileiro, mais uma vez em sua história, apresenta-se para a população de baixa renda em sua face predominantemente repressiva", segundo o Relatório Nacional para o Direito à Educação (2007). ${ }^{18}$

... avaliamos que o Estado brasileiro (executivo, legislativo e judiciário) viola sistematicamente os direitos humanos da população do Complexo do Alemão e de áreas similares, especificamente o direito humano à educação, ao manter uma baixíssima qualidade no atendimento educacional das crianças, jovens e adultos dessas comunidades - o que também ocorre em outros serviços sociais - e ao priorizar uma política de segurança pública de cunho militarista, que criminaliza a população de baixa renda, colocando-a recorrentemente sob risco de vida. (PLATAFORMA Dhesca Brasil, 2007:12)

Como proposta de combate à criminalidade, o governo do Rio de Janeiro criou as Unidades de Polícia Pacificadora (UPP), no ano de 2008. Elas têm “... por objetivo a retomada permanente de comunidades dominadas pelo tráfico, assim como a garantia da proximidade do Estado com a população." (O QUE É?, 2015). Não obstante a apresentação oficial, na prática, as UPPs se caracterizam pela ocupação ininterrupta militarizada, evitando os conflitos pontuais de grande violência, mediante a repressão ininterrupta nos territórios, tendo como resultante a "pacificação" ${ }^{19}$ dessas comunidades. Elas se inserem numa política internacional de combate ao

\footnotetext{
${ }^{16}$ Com vistas a garantir a segurança na cidade durante os Jogos Pan-americanos de 2007, o Complexo do Alemão foi alvo de uma grande operação, envolvendo 1.350 homens, no dia 27 de junho de 2007, resultando em 19 pessoas mortas oficialmente, com indícios de mortes sumárias e de que tenha havido ocultação de cadáveres. Vale esclarecer que as ações policiais em jogo são comumente relacionadas a uma onda de violência contra policiais, o que constitui "antecedente" à ocupação de 2007 (Ver: MATIOLLI, 2014).

${ }^{17} \mathrm{O}$ conceito de conflito armado vem sendo ampliado em função do contexto de violência, principalmente na América Latina. Inicialmente, entendia-se por "conflito armado" aquele restrito à situação de guerra. Hoje, amplia-se essa noção, abarcando um intenso conflito entre atores, com emprego ou potencial de emprego de violência, o que gera sofrimento, violação de direitos humanos e morte da população civil.

18 Para maiores informações, ver o Relatório Nacional para o Direito à Educação - Violação dos Direitos Educativos no Complexo do Alemão (Rio de Janeiro, 2007).

${ }^{19}$ Terminologia adotada pelos discursos oficiais de forma ampla e imprecisa. Entretanto, pelo contexto de sua criação, pelas justificativas apresentadas e pelo modus operandi, é possível relacionar as ideias de paz e pacificação à ideia de controle e domínio.
} 
narcoterrorismo. ${ }^{20}$ Até o ano de 2014 - quando se realizou, no Brasil, a Copa de Futebol Mundial da FIFA -, estava prevista a instalação de 40 UPPs no Rio de Janeiro.

Assim, o Estado brasileiro lança as Forças Armadas contra a população civil de seu próprio País, ou por meios diretos (mobilizando soldados), ou indiretos (mediante a ação de forças policiais treinadas e armadas pelo Exército). Hoje, o Brasil das UPPs serve como um laboratório avançado de práticas de repressão e controle de populações urbanas, algo que não se viu sequer no auge da ditadura militar. [...]

Num mundo em que a crise do capital faz aumentar a miséria, em que quase um bilhão de seres humanos passam fome e em que grandes cidades, repletas de "refugiados" internos e externos mais se assemelham a imensas panelas de pressão, as UPPs surgem como experimentos de vanguarda, um produto pronto e excelente para exportação Made in Brazil. (ARBEX Jr., 2014)

No Rio de Janeiro, a primeira UPP foi inaugurada no Morro de Santa Marta (Zona Sul do Rio de Janeiro), em 19 de dezembro de 2008. Em 2012, foi instalada a UPP do Complexo do Alemão, a UPP Nova Brasília e a UPP Fazendinha (18 de abril de 2012).

Seguindo o modelo reconhecido de Medellín, as intervenções urbanas - com destaque para os equipamentos de mobilidade - ganham protagonismo nessas ações. Assim, no Complexo do Alemão, além do teleférico e sua articulação com a supervia, a intervenção urbanística previu também a construção de 920 unidades habitacionais para relocação de famílias, a construção de um Espaço Esportivo - com campo de futebol, quadra poliesportiva, vestiário e bar de apoio -, e, ainda, a construção do Colégio Estadual Jornalista Tim Lopes ${ }^{21}$, de um Centro de Referência para a Juventude (CRJ) e de uma Biblioteca, totalizando $721^{22}$ milhões de reais, financiados pelo PAC2.

\footnotetext{
${ }^{20}$ Segundo Arbex Jr. (2014), a guerra ao narcoterrorismo data dos anos 80, tendo como maior agente os E.U.A., e se expressa pela repressão violenta sobre as populações mais pobres urbanas. Apesar do destaque mundial dos generais brasileiros, sua concepção envolveu agentes da CIA, do FBI e DEA - que abriram escritórios oficiais no Brasil, durante o governo do presidente Fernando Henrique Cardoso. Tal política foi mantida pelos governos consecutivos do Presidente Luis Inácio Lula da Silva e da Presidente Dilma Rousseff. Conta, ainda, com a participação de agentes israelenses, país fabricante dos "caveirões" (apelido dado aos veículos blindados para transporte pessoal, utilizados em incursões às favelas cariocas). Ainda segundo esse autor, o México e a Colômbia sofreram ações semelhantes.

${ }^{21}$ Homenagem a um jornalista investigativo morto por traficantes quando fazia uma matéria sobre o tráfico de drogas.

${ }^{22}$ Segundo o site da Prefeitura do Rio de Janeiro, o custo foi de 721 milhões. O IPEA informa o custo de R\$ 827.721.089,17 e, no site oficial do PAC, os valores chegam a $R \$ 967.414 .879,00$, sendo que $R \$$ 731.311.159,00 são recursos federais e R\$ 236.103.720,00 são recursos estaduais (Ver: PAC-RIO). R\$ $844.000 .000,00$ é o valor informado no material publicitários disponível no Fórum Mundial em Medellín dos investimentos no Complexo do Alemão.
} 
Em 2010, como um marco simbólico e um rito de passagem, assim como em Medellín ${ }^{23}$, a "ocupação" do Morro do Alemão foi divulgada e transmitida em escala mundial. ${ }^{24}$ Esse espetáculo despolitizou o político, deslocando, aos olhos dos demais, a natureza militar da megaoperação realizada no dia 28 de julho de 2010, quando os 2.700 agentes, em menos de uma hora, dominaram o território do Complexo do Alemão, numa operação de "guerra". ${ }^{25}$

A cobertura ao vivo, as manchetes e as notícias transformaram essa ação em espetáculo político-midiático: “A ocupação do Complexo do Alemão, na zona norte do Rio de Janeiro, 'cativou' os brasileiros como nenhum outro evento desde a Copa do Mundo da África do Sul, segundo o jornal The New York Times" (OPERAÇÃO..., 2010).

A segurança passa a ser um eixo estratégico da questão urbana, empresariada e tratada de forma segmentada e territorial. Com a concentração espacial da pobreza, as áreas pobres, nas cidades, ficam sob vigilância militar constante. Assim, os espaços ocupados pelos mais pobres sofrem dupla discriminação - territorial e social -, sendo comparados, metaforicamente, a "campos de concentração." (ARAUJO, 2010).

O projeto das Unidades de Polícia Pacificadoras (UPPs) foi aplaudido pela opinião pública como o resgate, por parte do Estado, de todas as áreas dominadas por traficantes, com seu vasto arsenal. Numa realidade em que helicóptero da polícia virou alvo dos fuzis, havia passado da hora de desarmar os "bandidos". Tamanho sucesso das UPPs, no governo de Sérgio Cabral, no Rio de Janeiro, que a presidente Dilma Rousseff já se pronunciou publicamente sobre, e declarou que irá expandir o modelo da política de Segurança Pública para além do território fluminense, no sentido de ampliálo em escala federal. (ARAÚJO, 2010)

A repressão e o controle militar sobre os bolsões de pobreza, na cidade formal, expressam e explicitam os territórios de segurança. Para Foucault (2009), a circulação de pessoas e coisas torna-se elemento estratégico ao exercício da soberania do Estado de polícia, inserida num processo chamado por ele de "governamentalidade". ${ }^{26}$

\footnotetext{
${ }^{23} \mathrm{~A}$ "operação "Orión" demarcou a ação do estado para o controle territorial em Medellín (Ver: COSTA, RAMIREZ, 2012)

${ }^{24}$ É importante relacionar essa ação ao processo de preparação para a agenda de megaeventos no Brasil, dentre os quais a Copa Mundial de Futebol de 2014.

25 A operação totalizou, oficialmente, 37 pessoas mortas, 118 prisões, 130 pessoas detidas para averiguações, 60 armas apreendidas, bem como 21 toneladas de maconha e 12 quilos de cocaína (TOTAL...2010). Segundo a Justiça Global, o número de mortos pode ser superior, tendo em vista as denúncias de ocultação de cadáveres e o número de desaparecidos apontados pelos moradores (Ver: MANIFESTAÇÃO... 2010).

${ }^{26}$ Por governamentalidade Foucault (2009) entende o conjunto de instituições, procedimentos, disciplinas e saberes, com destaque para a economia política, que visam ao poder, objetivando a população. Trata-se de
} 
Nesse caso, a gramática militar instrumental de opressão e repressão é exercida sobre a população mais pobre e historicamente fragilizada no Brasil, gerando as "cidades-sitiadas" (IVO, 2013). Obras urbanas, como a construção dos "ecomuros" em 2009, contribuem com o aparelho repressor, favorecendo o "encarceramento urbanístico" da pobreza e o controle do ir e vir dos cidadãos na cidade. Nesses "territórios sitiados", de potenciais "inimigos", estabelece-se um "contrato penitencial", e os residentes tornam-se, independentemente de suas condutas, suspeitos previamente julgados ou perdas necessárias ao bem comum. Num outro sentido, e complementarmente à ação repressora, as intervenções urbanísticas, como um rito de passagem, constituem um cenário para a construção simbólica de um novo tempo e um meio de ressignificação positiva da ação do Estado de polícia, violentamente exercida sobre os corpos e territórios.

Diferentemente das obras na Colômbia - resultantes, em sua maioria, de concursos públicos internacionais -, o projeto do teleférico no Rio de Janeiro foi solicitado a Jorge Mario Jáuregui - do Atelier Metropolitano -, quando o então governador do Rio de Janeiro, Sérgio Cabral, visitou Medellín. Na cerimônia de inauguração, a presidente afirmou: "O teleférico será visto por todos com olhos da boa inveja." (QUAINO, 2011).

A obra é alardeada como evidência da cidadania, ora tratada no campo político, significando também ganhos econômicos, pois permite instalar serviços públicos pagos e possibilita a abertura do "mercado do morro" às grandes empresas "do asfalto", estimado em 13 bilhões de reais.

Dilma Rousseff enfatizou que a cerimônia de inauguração do teleférico representava a comemoração "a esse respeito à cidadania dos moradores do Alemão". Ainda durante o discurso, a presidenta lembrou que, nesta data, inaugurou também uma agência dos Correios e um posto de atendimento do INSS. Os dois serviços a serem prestados à população, conforme ressaltou, permitirão as mesmas facilidades que são oferecidas em outros postos do país. (O TELEFÉRICO... 2011).

O Rio de Janeiro se apresenta no Fórum Mundial de Urbanismo em Medellín (Figura 04), e os projetos do Complexo do Alemão, da Rocinha e de Manguinhos estampam o material publicitário que enaltece numericamente esses eventos urbanos. O teleférico, com seus 3,5 quilômetros de extensão, é o maior da América Latina; suas 152 gôndolas, com capacidade para oito passageiros, transportam, em média, 12 mil passageiros por dia. Com o tempo de 16 minutos de viagem entre as estações extremas, sem dúvida, o teleférico impacta de forma positiva na

uma tendência ocidental que marca o processo histórico de protagonismo do poder de governo, marcando a transformação do Estado de justiça em Estado administrativo e, posteriormente, em Estado de polícia. 
qualidade de vida dos moradores. Os residentes no Complexo do Alemão, para usufruir de duas passagens gratuitas por dia, precisam efetuar um cadastro, comprovando o CPF e o endereço mais um instrumento de conhecimento da população residente e de controle indireto dessa população.

Figura 04
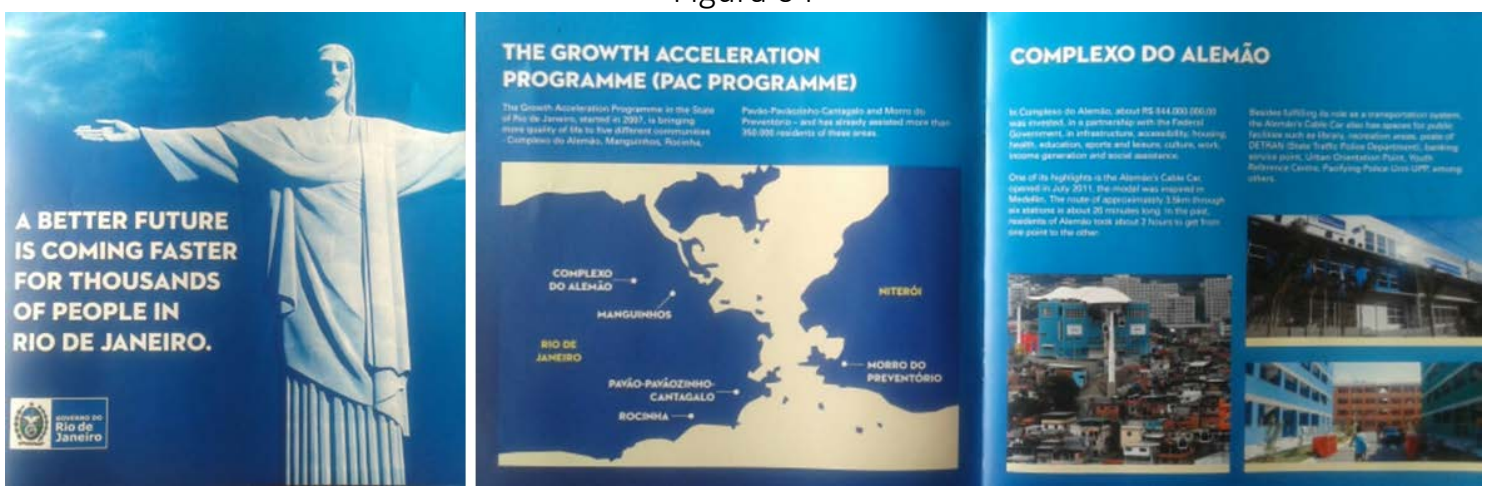

Fonte: Governo do Rio de Janeiro; EMOP

Assim, as intervenções urbanísticas no Complexo do Alemão favorecem a construção simbólica de valorização da cidade como produto de consumo mundialmente estabelecido, num sistema que alia a imagem, o simbólico e o econômico:

O conjunto de estações do sistema de teleférico do Complexo do Alemão constitui uma nova presença positiva na paisagem da cidade do Rio de Janeiro. Hoje, logo que o visitante chega à cidade através do aeroporto internacional do Galeão, ou enquanto espera no hall da sala de embarque para deixar a cidade, já percebe, claramente, quatro estações do teleférico que aparecem na paisagem, "colocando no mapa", literalmente, o Complexo do Alemão, antes estigmatizado e "invisível" para o cidadão comum e agora associado a uma nova condição de cidadania, passando de área de exclusão para área de visitação. (HELLM, 2011)

Nos territórios de moradia das camadas populares, na cidade consolidada, a naturalização da violência do Estado - expressa pela presença contínua de agentes policiais armados ou do exército, com os tanques de guerra, etc. - é favorecida pela representação simbólica da ideia de liberdade e paz proporcionada pela operação. Esse contexto, marcado pela presença do Estado e representado pela presença militar, é apresentado como um "passo decisivo para vencer a bandidagem que ganhou poder sob a complacência de governos populistas". ${ }^{27}$ Nesse enredo, os

\footnotetext{
27 "Por uma semana, atentados em série promovidos pelo tráfico espalharam o medo e mudaram a rotina do carioca. O estado decidiu revidar. Com apoio das Forças Armadas, uma megaoperação policial acuou centenas de traficantes na zona norte e tomou duas de suas trincheiras, a Vila Cruzeiro e o Complexo do Alemão. É um passo decisivo para vencer a bandidagem que ganhou poder sob a complacência de governos populistas." (TERROR...2010).
} 
militares são tratados como heróis, e a desconfiança e a violência - inclusive a física - paira sobre todos que residem nas áreas de ocupação dos segmentos mais pobres da cidade.

A violência continuada da vigília repressora, nesses territórios, torna-se parte do cotidiano desses moradores: casos de execução não registrados, ocultação de cadáveres e desaparecimento de pessoas são apontados pela Justiça Global Brasil (MANIFESTAÇÃO... 2010). São informações que, normalmente, não aparecem na imprensa nacional ou internacional. Sob a insustentável tese de um "estado de flagrância abrangendo toda a comunidade" 28 e a expedição de mandados de busca e apreensão coletivos, o cotidiano dessa população é marcado pela incerteza das constantes invasões domiciliares, pela vistoria de pessoas e pelo controle sobre o ir e vir que, somados à presença ostensiva militar, levam ao questionamento sobre o estado de direito, nessas áreas.

Os casos de arrombamento de porta são fartos no Complexo do Alemão e na Vila Cruzeiro. "Não é permitido entrar na casa de ninguém sem mandado. Isso é ilegal", afirma Ignácio Cano, do Laboratório de Análise da Violência da UERJ. Embora seja, de fato, proibida, a ação é historicamente comum em favelas no Rio de Janeiro. Como muitas, essa é uma lei que não vale para regiões pobres da cidade. Entretanto, nas ocupações recentes da Zona Norte, a lei nunca foi tão desrespeitada. Como há, na região, todos os tipos de polícia, além do Exército, uma mesma casa está sendo invadida mais de uma vez. Tem sido comum moradores próximos se unirem para vigiar as casas dos vizinhos. "Muita gente está perdendo oportunidade de emprego, porque tem que ficar em casa vigiando nossas casas de quem deveria protegê-las", acusa a moradora Solange. Quem anda pelas favelas da região encontra incontáveis bilhetes colados na porta. "Senhores policiais, não estou em casa porque estou trabalhando. A chave está com a vizinha do lado. O nome dela é Patrícia", diz uma das mensagens. (UCHOAS, 2010)

Tal violência, vivida cotidianamente pelos moradores do Complexo do Alemão, é naturalizada em matérias como: "Vida normal no Complexo do Alemão - Após invasão militar, moradores do Complexo do Alemão retornam ao seu cotidiano" (VIDA...2011). Esse é o título de uma série de imagens do fotógrafo Ismar Ingber, publicadas pela revista Veja e que retratam o dia a dia desses moradores, com a presença ostensiva do poder militar do Estado. Assim, a "normalidade" do controle cotidiano exercido violentamente pelo Estado sobre os cidadãos moradores dessas áreas - é restabelecida: agentes do Exército fortemente armados, garantindo a segurança nas feiras locais; tanques desfilando pelas ruas, em meio às brincadeiras das crianças; moradores sendo vistoriados ao ir para o futebol etc. Esses são retratos do dia a dia dos moradores do Complexo do Alemão.

\footnotetext{
${ }^{28}$ Ver: A (I)LEGALIDADE..., 2011).
} 
A imagem de normalidade - com a naturalização do controle militar sobre os cidadãos mais pobres nas cidades, a pacificação dos territórios de pobreza, mediante a militarização constante como expressão da presença do Estado, e o teleférico, como ícone de cidadania - ganha as telas na narrativa da novela Salve Jorge, passando uma mensagem positiva da pacificação do Complexo do Alemão, protagonista do espetáculo mundialmente comercializado, retirando o caráter repressor do processo real vivenciado e ainda vivido pelo cotidiano dos moradores do espaço urbano nessas comunidades. "A autora da telenovela, Gloria Pérez, disse que o 'resgate' da população, 'reprimida por bandidos durante tantos anos', a impressionou e emocionou." (ESTREIA...2012).

Considerando os efeitos desse processo pacificador sobre a subjetividade dos moradores das áreas ocupadas com investimentos na militarização e os discursos de cidadania e de paz, fica uma pergunta. Como uma macropolítica pacificadora atuou na formação subjetiva de indivíduos ou grupos nas favelas, em Medellín e no Rio de Janeiro, como micropolítica? Provavelmente, na forma de um consenso, e não, propriamente, a de um dissenso criativo à macropolítica da subjetivação da "ordem" e da hegemonia do mercado, o que, nesse caso, se expressa em modelos urbanos mundialmente aplaudidos e reverenciados como eficazes e efetivos na construção das cidades cidadãs, em áreas periféricas: obras fantasmagóricas dos reais processos repressores em jogo.

\section{CONSIDERAÇÕES FINAIS}

Analisar os paralelos entre as intervenções em Medellín e as ocorridas no Rio de Janeiro constitui um desafio. Se, de um lado, esses dois casos apresentam traços comuns de formas e sentidos da intervenção urbana e comungam de um contexto de pobreza estrutural partilhado pelos países latino-americanos, o que justificaria a adoção de soluções similares, de outro lado, apesar da identificação desses determinantes macroestruturais convergentes, cada uma das cidades apresenta e explicita contextos históricos singulares. Esse paradoxo, aparentemente óbvio nos estudos comparativos, nos obriga a tratar a adoção do modelo Medellín no contexto brasileiro com cautela, especificamente em relação às intervenções de pacificação do Complexo do Alemão.

O modelo colombiano se apresenta como capital simbólico. Nesse sentido, a adoção da solução do teleférico, além de facilitar o transporte de moradores e visitantes e de funcionar como instrumental de controle do território, serve como marco político e simbólico no espaço urbano. A magnitude e a imponência das torres que se destacam sobre a amplitude das ocupações irregulares facilitam relacionar a história de Medellín no combate ao tráfego e o seu 
reconhecimento mundial como estratégia de devolução dessas áreas à cidadania com as ações simbólicas da pacificação no Complexo do Alemão.

E assim, mais do que a efetiva transformação das condições e da qualidade de vida dos moradores, como compromisso com a edificação de uma cidadania por vezes inexistente, entendemos que o teleférico materializa, simbolicamente, a pacificação, sem que, necessariamente, os direitos fundamentais desses moradores sejam reconhecidos ou efetivados no cotidiano dessas comunidades. A ação do Estado se faz presente e forte não pela oferta de serviços públicos de qualidade, mas pela intermitente ação repressora e de controle sobre o território da pobreza urbanisticamente identificado como pertencente a supostos "inimigos" da cidade legal.

Obviamente, esse modelo de intervenção, de forte poder simbólico, teve alguns ganhos. Entretanto, a fragilidade do projeto se expressa na contramão desses ganhos, pelo caráter violento que marca a ação dos agentes sobre a vida dos moradores. Eventos violentos ganham força midiática e representam a falência da pacificação nos moldes atuais, fundamentalmente estruturada em ações de repressão e controle, quando o poder de polícia de Estado ultrapassa seus limites.

Algumas mortes são emblemáticas e caracterizam a ação da polícia no Rio de Janeiro: Amarildo $^{29}$ e Cláudia ${ }^{30}$ são alguns casos que envolvem a ação policial na capital fluminense. Tais casos se contrapõem, num outro sentido, à ideia de "pacificação", expressando a imagem repressora da polícia. No dia 02 de abril de 2015, o menino Eduardo - de 10 anos $^{31}$ - morreu vítima de um tiro efetuado por policiais no Morro do Alemão, que confundiram o celular da criança com uma arma. As tensões abafadas e contornadas pelo discurso da pacificação, cotidianamente vivenciadas pela população na forma de repressão, explodem em indignação nas manifestações de moradores clamando por justiça que ganham as ruas próximas à comunidade, exibindo a perversidade implícita ao "canto da sereia" desses modelos de intervenção. O Complexo do Alemão, mais uma vez, torna-se cenário de guerra pela ação violenta da polícia e das gangues do tráfico, denunciando abertamente o conflito que marca historicamente a relação do Estado (quer por sua ausência, quer seja por sua presença) com os estratos mais empobrecidos no tecido urbano consolidado de grande parte das cidades brasileiras.

\footnotetext{
29 Disponível em: <http://www.jusbrasil.com.br/topicos/26891868/caso-amarildo>. Acesso: 21 abr. 2015

30 Disponível em: < http://g1.globo.com/rio-de-janeiro/noticia/2014/03/arrastada-por-carro-da-pm-do-riofoi-morta-por-tiro-diz-atestado.html >. Acesso: 21 abr. 2015.

${ }^{31} \mathrm{http}$ //fotografia.folha.uol.com.br/galerias/33929-moradores-do-alemao-protestam-apos-morte-demenino\#foto-499132.
} 


\section{REFERÊNCIAS}

AGAMBEM, Giorgio. Estado de exceção. São Paulo: Boitempo, 2004.

A (i) legalidade da busca e apreensão e as operações do Complexo do Alemão e na Vila Cruzeiro Estado de Direito para quem. Agencia de Noticias das Favelas, 2011. Disponível em: < http://www.anf.org.br/a-ilegalidade-da-busca-e-apreensao-e-as-operacoes-policiais-no-complexodo-alemao-e-na-vila-cruzeiro-\%E2\%80\%93-estado-de-direito-para-quem/\#\#. VN5uqC5DQtc> . Acesso em: 13 fev. 2015.

ARAÚJO, Luciana. UPPs transformam favelas cariocas em campos de concentração. Brasil de Fato, São Paulo, 09 dez. 2010. Disponível em: <http://www.brasildefato.com.br/node/5263>. Acesso em: 15 dez. 2010.

ARBEX Jr . José. Facismo made in Brazil. O País das UPPs desenvolve e exporta tecnologias de controle militar de populações urbanas. Revista Caros Amigos. Maio 2014. p. 9.

CARTA a Medellin. Soluciones Urbanas - Plataforma. Disponível em: www. Solucionesurbanas.org

COSTA, Grazielle; RAMÍREZ,IvánDarío. Para além da "guerra" e da "paz": Territórios de violência em Medellín. P: 117-132. In: Revista Crítica de Ciências Sociais, 96, Março 2012: 117-132.

Estreia primeira novela ambientada em comunidade pacificada, 2012. Disponível em: < http://exame.abril.com.br/estilo-de-vida/noticias/estreia-primeira-novela-ambientada-emcomunidade-pacificada >. Acesso em: 14 fev. 2015.

KOPSCHITZ, Isabel. Pacificação do Complexo do Alemão vira tema de novela. 22/10/2012. Disponível em: <http://www.rj.gov.br/web/imprensa/exibeconteudo?article-id=1288179>. Acesso em: 31 jan. 2015.

HELM, Joanna. Teleférico do Complexo do Alemão / Jorge Mario Jáuregui. 11 nov. 2011. Disponível em: <http://www.archdaily.com.br/br/01-7796/teleferico-do-complexo-do-alemao-jorge-mariojauregui> Acesso em: 01 fev.2015

Salvador: EDUFBA, 2015.GÜTHER, Jakobs; MELIÁ, Manoel Cancio. Direito Penal no Inimigo: noções e críticas. Porto Alegre: Editora do Advogado, 2007.

GUZZI, André Cavaller. As Relações Eua-America Latina: Medidas e Consequencias da Política Externa Norte- Americana para Combater a Produção e o Tráfico de Drogas llícitas. 2008. Dissertação (Mestrado em Relações Internacionais) - PUC SP/UNESP/ÚNICAMP.

Manifestação Pública de Organizações de DH sobre Alemão e Vila Cruzeiro.Justiça Global Brasil. 21 dez. 2010. Disponível em: < http://global.org.br/programas/manifestacao-publica-de-organizacoesde-dh-sobre-alemao-e-vila-cruzeiro/>. Acesso em: 14 fev. 2015.

MATIOLLI, Thiago Oliveira Lima. Gestão urbana e controle da circulação: as operações policiais (2007 e 2010) no Complexo do Alemão (RJ).Anais [...]V SEMINÁRIO NACIONAL SOCIOLOGIA \& 
Política. 14 a 16 de maio de 2014, Curitiba - PR. Disponível em: < http://www.humanas.ufpr.br/portal/seminariosociologiapolitica/files/2014/08/24666_139771379 2.pdf>. Acesso em: 14 fev. 2015.

O que é? Disponível em:<http://www.upprj.com/index.php/o_que_e_upp >. Acesso em: 14 fev. 2015.

O teleférico do Alemão é um símbolo do PAC, diz presidenta Dilma. 7 jul. 2011. Disponível em: $<$ http://blog.planalto.gov.br/o-teleferico-do-alemao-e-um-simbolo-do-pac-diz-presidenta-dilma/>. Acesso em: 13 fev. 2015.

PAC-Rio. Disponível em: <http://www.chs.ubc.ca/consortia/events/E-20080916/GovernoRJComplexo_do_Alemao.pdf> Acesso: 01 fev 2014.

PIRES. Carol. A guerrilha na mesa. Revista Piauí, ano 8, n. 92. Maio 2014.

PLATAFORMA Dhesca Brasil. Relatório Nacional para o Direito à Educação - Violação dos Direitos Educativos no Complexo do Alemão (Rio de Janeiro), 2007. Disponível em: < http://www.cedaps.org.br/wp-

content/uploads/2013/07/relatoriocompletomissaocomplexoalemao.pdf>. Acesso em: 14 fev. 2015.

Presidente da Colômbia destaca a importância da educação superior para o desenvolvimento regional. 2008. Disponível em: <https://www.ufmg.br/online/arquivos/008808.shtml>. Acesso em: 20 jan. 2015.

Operação policial "cativou" público brasileiro como na Copa, diz "NYT". Folha de São Paulo, São Paulo, 29 nov. 2010. Disponível em: <http://www1.folha.uol.com.br/cotidiano/837707-operacãopolicial-cativou-publico brasileiro-como-na-copa-diz-nyt.shtml>. Acesso em: 05 mar. 2012

SOBRAL, Lilian. Os países com as maiores taxas de homicídios do mundo. 2013, disponível em: $<$ http://exame.abril.com.br/mundo/noticias/os-paises-com-as-maiores-taxas-de-homicidios-nomundo>. Acesso em:20 jan. 2015.

Terror no Rio. 2010. Disponível em:< http://veja.abril.com.br/tema/terror-no-rio >. Acesso em: 14 fev. 2015.

Total de mortos no Rio chega a 37, segundo balanço da PM. 29 nov. 2010. Disponível em: < http://noticias.uol.com.br/cotidiano/ultimas-noticias/2010/11/29/total-de-mortos-no-rio-chega-a37-segundo-balanco-da-pm.htm>. Acesso em: 14 fev. 2015.

UCHOAS, Leandro. As violações de direitos no Complexo do Alemão e na Vila Cruzeiro. Brasil de Fato, 21 dez. 2010. Disponível em: <http://www.brasildefato.com.br/node/5339>. Acesso em: mar. 2011.

VALDERRAMA, Sergio Fajardo. Coneducación y legalidad estamos transformando a Antioquia. Disponível em: <http://antioquia.gov.co/index.php/prensa/historico/23574>. Acesso em: 20 jan. 2015. 
Vida normal no Complexo do Alemão- Após invasão militar, moradores do Complexo do Alemão retornam ao seu cotidiano. 2010. Disponível em: < http://veja.abril.com.br/multimidia/galeriafotos/vida-normal-no-complexo-do-alemao/ >. Acesso em: 06 jun.2011.

ZIZEK, Slavoj. Violência - seis reflexões laterais. São Paulo: Boitempo, 2014.

Trabalho enviado em 10 de outubro de 2015.

Aceito em 08 de março de 2016. 